\title{
Vicente Blasco Ibáñez, Pío Baroja y el comercio del libro en los Estados Unidos
}

\author{
Vicente Blasco Ibáñez, Pío Baroja \\ and Book Trade in the United States
}

\author{
Fernando Ariza González \\ Universidad CEU San Pablo \\ fernando.ariza@ceu.es \\ ORCID iD: https://orcid.org/0000-0001-7199-0273
}

\section{RESUMEN}

Tanto Vicente Blasco Ibáñez como Pío Baroja fueron ampliamente publicados en los Estados Unidos y disfrutaron de una relación profesional y personal con sus editores. Sin embargo, el modo en el que ambos afrontaron su entrada en el país les diferenció completamente: Blasco aceptó la modernidad de un mercado mucho más avanzado e incluso aportó ideas para promocionar su obra, mientras que Baroja fue más reaccionario y le costó adaptarse a ese nuevo modo de relacionarse con el público lector. A través de la correspondencia con sus editores vamos a comprobar cómo ambos se manejaron en este nuevo contexto.

Palabras Clave: Vicente Blasco Ibáñez; Pío Baroja; relaciones culturales; historia de la edición; promoción editorial; literatura española en el extranjero; correspondencia.

\begin{abstract}
Vicente Blasco Ibáñez and Pío Baroja were widely published in the United States and had both a professional and personal relationship with their publishers. However, Blasco accepted the modernity of an advanced market and even offered new ideas to promote his work, Baroja was more unreceptive and had more problems to interact with his readers. Throughout their correspondence, we will see how they handled in this new context.
\end{abstract}

Key words: Vicente Blasco Ibáñez; Pío Baroja; Cultural relations; History of publishing; Editorial promotion; Spanish literature abroad; Correspondence.

Los dos autores españoles que más y mejor se vendieron en los Estados Unidos en la primera mitad del siglo XX fueron Vicente Blasco Ibáñez y Pío Baroja, si bien el volumen de ventas y el número de libros dista mucho entre 
uno y otro. Blasco publicó más de treinta obras en esos años, mientras que Baroja apenas llegó a una decena. Eso sí, ambos crearon un fuerte vínculo con sus editores John Macrae de Dutton y Alfred Knopf. El principal contraste entre ambos escritores, provocado probablemente por sus antagónicas personalidades, se vio en el modo en el que se enfrentaron a un mercado editorial mucho más moderno que el español. Las editoriales norteamericanas desde principios del siglo XX se habían convertido en empresas modernas, orientadas a un público amplio, a las grandes ventas, y por lo tanto conscientes de la importancia de la publicidad. Las editoriales españolas seguían gestionándose de una manera casi artesanal, donde se confundía la profesión de impresor, editor y librero y las estrategias publicitarias se reducían, en el mejor de los casos, a hacer unas cubiertas a color (Sánchez García 2001, 248). Los dos novelistas reaccionaron de una manera radicalmente diferente a esta nueva realidad. El valenciano no solo aceptó las nuevas reglas, sino que fue el primero en sugerir nuevas estrategias promocionales mientras que el vasco fue reticente a casi todas las peticiones comerciales de su editor.

La novela de Blasco Ibáñez, Los cuatro jinetes del Apocalipsis, tuvo un enorme e inesperado éxito en los Estados Unidos. Fue publicada por la editorial Dutton en los primeros meses de 1919 y en poco tiempo vendió más de un millón de ejemplares. No era el primer libro que el valenciano publicaba en aquel país. Sin ir más lejos, un año antes la editorial Knopf había publicado una traducción de La barraca, pero apenas tuvo repercusión entre la crítica o el público. Probablemente el éxito de The Four Horsemen of the Apocalypse se debiera a la oportunidad de su aparición, pues era un libro sobre la Primera Guerra Mundial escrito desde el punto de vista de los Aliados justo en el momento en el que los Estados Unidos entraban en el conflicto, por lo que «el lector norteamericano, poco conocedor de la historia europea, podía encontrar en el libro una justificación de la guerra, acaso una información sobre las razones que amparaban la participación de su país en el conflicto» (Varela 2017, 733).

La novela apareció publicada en la editorial neoyorkina Dutton. Al ver el éxito del libro, apostaron por el resto de la obra de Blasco Ibáñez. Al cabo de los años le publicaron más de treinta novelas. El director editorial, John Macrae, mantuvo una relación epistolar con el valenciano que comenzó siendo puramente profesional y terminó, al cabo de los años, como una amistad cordial (Blasco Ibáñez y Macrae 2017). A través de su correspondencia se descubre un aspecto poco conocido del novelista, pues gran parte de los asuntos de las cartas, más que sobre literatura, giraba en torno a cuestiones puramente editoriales. La actitud comercial del norteamericano, mucho más pragmática que la figura tradicional de un editor español, despertó en Blasco su naturaleza de hombre de negocios y le llevó a proponer ideas extraordinariamente novedosas para promocionar sus libros. Transmitió esa misma idea a su editor francés, a quien le escribe que «La propaganda lo es todo» añadiendo que debían «mover el negocio editorial al estilo americano» (Botrel 2012, 148). 
Blasco siempre estuvo vinculado con el mundo editorial. En 1898 montó, junto con el librero Francisco Sempere, la Casa Editorial F. Sempere'. Más adelante, ya en Madrid, fundó la editorial Española Americana y, en fechas cercanas al momento de su llegada a América, la conocida Prometeo, que surgió en 1914. Si bien sus primeros proyectos editoriales poseían un claro interés ideológico, con el paso del tiempo «Blasco acentuó el valor crematístico de su actividad y, progresivamente despegado de posiciones combativas, buscó incrementar su éxito como escritor, mas también como editor» (Lluch-Prats 2015, 1621). En los tiempos de Prometeo ya había comprendido que una editorial tiene un componente empresarial básico y que la venta de libros está basada tanto en la calidad literaria de los textos como en aspectos formales y simbólicos. Le dedicó un esfuerzo poco habitual a que las cubiertas de sus libros fueran llamativas y de calidad, para lo cual contó con los mejores ilustradores de la época: Francisco Povo, Arturo Ballester y Rafael de Penagos (Varela 2017, 774).

También sabía que su imagen de figura pública y de escritor podía servir de reclamo al público casi tanto como una bonita imagen, por lo que «una vez su nombre había adquirido notoriedad, lo utilizó como reclamo publicitario, y así como capital simbólico que incrementó al hacer de sus actividades editoriales vehículo de expresión y de atracción tanto ideológica como personal» (Lluch-Prats 2012, 92). Era común encontrar en las cubiertas su nombre, bien como versionador, revisor del texto o escritor de la introducción.

Su labor como publicista no llegó a mucho más en España, pero el tono que descubrió en América, mucho más abierto a las innovaciones y con muchos menos complejos comerciales, despertó en él su vena de comerciante y le ayudó a desarrollar toda una batería de acciones orientadas a la venta de sus libros. Lo sorprendente de varias de ellas, como veremos, es su carácter premonitorio, pues muchas de las propuestas son hoy en día habituales o incluso obligatorias en el mercado editorial español.

Es muy revelador que uno de los artículos que publicó para The New York Times tuviera como título «El novelista como hombre de negocios» ${ }^{2}$ (Blasco Ibáñez 1921). Comienza el artículo diferenciando la imagen americana de la europea: «en Europa se tiene por asumido que el hombre de letras debe ser un arruinado mientras que el hombre de negocios, en lo referente a todo lo artístico, un lerdo» ${ }^{3}$, y confirma con ironía la idea de la general opinión que tiene la gente sobre las diferencias que existen entre el escritor y el dinero: «El

\footnotetext{
${ }^{1}$ Se ha publicado parte de la correspondencia entre Blasco y su editor español (Blasco y Sempere 1999), pero desgraciadamente termina en 1917, por lo que no sirve para completar la información de este artículo.

2 «Novelists as Business Men». Las traducciones del inglés son mías.

3 «In Europe it is safe and sane to asume that the man of letters must be a beggar; while the business man, in regard to everything artistic, must be a dolt».
} 
mundo se empeña en que un gran escritor, si es realmente grande, debería vivir en la pobreza y morir de hambre; y es comúnmente sabido que la penuria es una de las condiciones más favorables para el desarrollo del genio» ${ }^{4}$. Da como ejemplo característico del supuesto desapego que el novelista debería tener hacia el dinero el poco y tardío desarrollo de las leyes de propiedad intelectual frente a la histórica importancia de las leyes de propiedad física. Blasco era consciente de estos errores y vacíos en la ley, pues sus libros habían sido pirateados sin mayores problemas en varios países americanos, aunque en ese momento probablemente tenía en la cabeza el fallo técnico que había cometido en el contrato de traducción de su novela Los cuatro jinetes y que le ocasionó la pérdida de la mayor parte de las regalías (Ariza 2018).

Termina el artículo con extensos ejemplos de narradores conocidos (Balzac, Lamartine y Victor Hugo) que fueron también hombres de negocios con mayor o menor éxito. Secretamente él se incluye en ese grupo, pues fue negociante en Argentina; y en los Estados Unidos había empezado a ganar dinero con sus libros. El motivo de estos ilustres ejemplos era, probablemente, un modo de legitimar sus actos frente a quienes le podrían criticar por tener cierta disposición hacia lo crematístico.

El contenido esencialmente práctico de las cartas escritas a su editor John Macrae, serán el ejemplo más contundente de las ideas expuestas en el párrafo anterior. El mercado editorial norteamericano estaba mucho más desarrollado que el español ya en aquella época, por lo que el uso de la publicidad, la imagen del libro o la presencia pública del autor tenían enorme importancia en la venta de los libros. Blasco se sintió muy cómodo con ese rasgo distintivo, olvidó los prejuicios hispánicos y se permitió dar rienda suelta a todas sus iniciativas. Lo más llamativo del asunto es que varias de ellas fueron novedosas incluso para los editores americanos. Vamos a ver cómo desarrolla toda una serie de propuestas de mercadotecnia y publicidad para favorecer la venta de sus libros.

Blasco Ibáñez sabía de la importancia del autor a la hora de vender nuevos libros. Hemos mencionado cómo utilizaba su nombre como reclamo publicitario en la editorial Prometeo. En los Estados Unidos, y a pesar del gran éxito de The Four Horsemen of the Apocalypse, era aún un autor del que no se sabía mucho, al menos en comparación con lo conocida que era su figura en España. Él es consciente de este desconocimiento, y también sabe que «en los Estados Unidos algunas de las biografías que se han publicado han estado llenas de errores y equivocaciones» (Blasco Ibáñez y Macrae 2017, 29) ${ }^{5}$, por lo que le

\footnotetext{
${ }^{4}$ «The world insists that a great writer, if he is really great, shall live in proverty and die of starvation; and it is commonly believed that penury is one of the favorable conditions for the development of genious».

${ }^{5}$ Debido a que van a aparecer numerosas referencias al epistolario entre Blasco y Macrae, a partir de ahora solo las indicaremos con el número de página.
} 
envía al editor «una precisa nota biográfica» e indica que «pueden usar este material si desean un nuevo prefacio para alguna de mis novelas» (29). Pero no solamente considera importante que se conozca su biografía (es decir, sus méritos intelectuales, literarios y políticos), sino también su imagen física, aunque esta no conlleve ningún mérito especial. El valor icónico de la fotografía favorece que los lectores sientan al autor de una manera más cercana, lo asocien al nombre y por ende a otros futuros títulos. Por ese motivo muy pronto le escribe al editor diciéndole que «junto con este correo les estoy enviando varias fotografías mías para que se usen en los anuncios» (34). Con esto, aun sin saberlo, está contribuyendo a lo que más adelante se ha llamado «crear una imagen de marca», es decir, darle al novelista un tratamiento similar al que se le podría dar a cualquier otro producto. El nombre del autor y su imagen son retenidas en la mente del lector como una marca comercial que garantiza la calidad de ciertos productos que en este caso serán los libros que escribe. Con esto se logra que las siguientes novelas del autor se vendan con más facilidad, pues «la marca» está prestigiada. Insiste en otra carta en la importancia de aparecer con profusión en los diarios: «Lo que sí quiero es que las anuncien mucho y den una gran publicidad a mis obras, porque eso es tan importante para su editorial como para mí» (34).

La propia editorial tiene interés en la creación de esa imagen de marca: si consigue ser reconocible y se la asocia a autores concretos, ganará en visibilidad ante el público lector y nuevos autores verán prestigiada su obra desde un primer momento. Como buen editor, parece que Blasco Ibáñez ya intuía la importancia de que se asociara a un autor con una única editorial, por lo que en el momento que vio el prestigio de Dutton, les propuso que fueran ellos sus únicos editores: «Estoy muy contento de que sean ustedes mis editores en el idioma inglés para todos los países que hablan ese idioma, confiando en que su editorial va a poner anuncios para que mis libros circulen y sean leídos y se hable de ellos en los periódicos, porque por supuesto que también tengo interés económico» (20).

Un asunto relacionado con la imagen de marca, además de los vistos hasta ahora, y relacionado con la imagen del autor, es la propia presencia física del mismo. Para el público americano, un novelista español era algo distante y extraño. Si consideramos el tiempo que llevaban los trayectos en aquellos años y la poca comunicación que había entre ambos países (que habían salido, no hacía demasiado tiempo, de una breve pero mediática guerra). En ese contexto, Blasco Ibáñez tomó la decisión personal de convertirse en una figura cercana a su público: que le pusieran cara, voz y nombre. De la parte publicitaria ya se encargaba la editorial, pero aún quedaban muchos aspectos que dependían de él:

Habla Ud. en el cablegrama del dinero gastado en popularizar mi nombre en América. Lo agradezco mucho. Pero creo llegado el momento de trabajar yo por mi parte en este sentido y la mejor manera como puede hacerlo un escritor es 
escribiendo en los periódicos del país, para crearse una gran masa de lectores acostumbrados a leerle» (50).

La relación entre periodismo y literatura siempre ha sido próxima. Desde el siglo anterior, muchos escritores habían aprovechado los beneficios económicos de la prensa para mantener una profesión de novelista poco lucrativa. Sin embargo, no fue hasta muy avanzado el siglo XX cuando se vio la escritura en medios de comunicación de modo inverso. El propio escritor es quien se beneficia, pues enriquece su «marca» al crear vínculos más personales con el lector, que se acostumbra, como dice Blasco, a leerle no ya cada vez que publica una novela, sino de una manera mucho más constante.

En la misma carta, el valenciano da muestras de su «energía americana» y expone las últimas gestiones que ha hecho al respecto:

Me he puesto en relación con The Foreign Press Service y su director M. Arthur Livingstone, que son agentes literarios de todos los grandes diarios. Voy a empezar desde hoy a enviarles artículos para los diarios, cuentos para los magazines, etc. Yo soy hombre de actividad y buscaré que mi nombre aparezca continuamente en los grandes diarios. Veremos si lo consigo. Esto influirá mucho en la venta de los libros (50).

Efectivamente, en los años sucesivos vamos a ver que Blasco se convierte en un escritor habitual en la prensa norteamericana. Publicará artículos y cuentos en los principales periódicos del país: The Washington Post, Los Angeles Times, The Chicago Daily Tribune... (Caballer Dondarza 2007). Su actividad se multiplicará durante el viaje a América del que ahora hablaremos, llegando a ser el principal corresponsal del New York Times para cubrir la revolución mexicana ${ }^{6}$.

James B. Pond, dueño de una compañía especializada en organizar giras de conferenciantes por todo el país, se puso en contacto con él para llevarlo a los Estados Unidos. Blasco le escribió a Macrae: "Yo he contestado afirmativamente. Estoy dispuesto a hacer el viaje si lo organizan bien, es decir si cuentan con los periódicos, para hacer propaganda y llamar la atención del público» (39). Y añade: «si se organizase con buena publicidad, sería muy beneficioso para la casa Dutton, pues serviría para aumentar la venta de libros» (40). Esto indica que, aunque le da importancia al viaje en sí, sobrepone a sus gustos por conocer el país el interés del viaje como mecanismo de promoción de sus libros.

Consciente de la importancia que suponía la primera imagen que ofreciera ante el público americano, desplegó desde el principio toda su energía para hacerse notar a la prensa. Y lo consiguió. Entre 1919 y 1920 hemos contabilizado más de doscientas noticias centradas en él (124-139). Por este motivo,

\footnotetext{
${ }^{6}$ Artículos que luego unificaría en 1920: Mexico in Revolution (Blasco, 1920a) y en español, El militarismo mejicano (Blasco, 1920b).
} 
tuvo una actitud hacia los periodistas cercana y abierta: «Blasco Ibáñez el cercano» titularon uno de los primeros artículos (Moses 1919). Supo dar al pueblo americano muestras de su interés hacia ellos y no dejó de elogiarles cuanto pudo. Entre sus declaraciones laudatorias podemos encontrar: «El fútbol americano es tan emocionante como una corrida de toros $\rangle^{7}$ (Boston Daily Globe, 23 de noviembre de 1919) o «Ibáñez juzga a los Estados Unidos como lo más grande del mundo» ${ }^{8}$ (The Boston Daily Globe, 28 junio de 1920). Llegó a decir que le gustaba tanto el país que había decidido comprarse una casa en Nueva York (Varela 2017, 741). Además de complaciente, también supo poner su punto de polémica, que siempre encendía el interés: «Ibáñez llama a los americanos cobardes delante de sus mujeres» ${ }^{9}$ (The Chicago Daily Tribune, 29 de febrero de 1920) o «la comida americana es algo frívola» (Montague 1920). El resultado, como hemos dicho, no pudo ser mejor para él y para la editorial. En apenas algo más de un año, Blasco Ibáñez pasó de ser un raro escritor extranjero a convertirse en el español más conocido de todos los Estados Unidos de América.

Blasco Ibáñez tenía la clara intención de triunfar con sus libros en América: "Yo he sido siempre republicano federal y gran admirador de los Estados Unidos. Una de mis grandes ilusiones ha sido conocer de cerca esa gran nación. ¡Imagínense con qué gusto iré a verla!...» (39). Por ese motivo, ya desde el principio hizo esfuerzos por simpatizar con el carácter estadounidense. En una carta, expone las posibilidades comerciales de sus novelas publicadas y de los nuevos proyectos. Opina que Cañas y barro es su mejor novela, porque «es un trabajo de juventud: intenso, vigoroso y muy dramático. Muchos críticos están de acuerdo conmigo sobre este punto. Incluso los menos amistosos colocan a esta novela por encima de las demás» (28). Sin embargo, no la recomienda para los lectores americanos y en su lugar propone otra novela menor:

Insisto en que Los Argonautas será un gran éxito en los Estados Unidos si se publicita adecuadamente y se muestra como una novedad. Es un libro que despertará más interés en América que en cualquier otro país. Es una novela sobre el descubrimiento de América, pero moderna y precisa, sin mentiras ni leyendas. $\mathrm{Su}$ lectura cambiará radicalmente muchas ideas viejas y falsas (24).

Tiene, sin embargo, una duda respecto a ese libro: «Hay en Los Argonautas un tipo de señora algo aventurera que no es antipática pero tampoco simpática. Esta señora es de los Estados Unidos, porque el tipo que yo tomé del natural lo era, y no pensé en aquel momento en cambiar su nacionalidad» (67). Menciona que ya antes ha tenido algún problema por haber escrito asuntos similares sobre naciones y sus ciudadanos: «Hay que tener miedo a las susceptibili-

\footnotetext{
7 «Football Exciting as a Bull Fight».

8 «Ibáñez Judges U.S. Greatest in World. Special Dispatch to the Globe».

9 «Ibáñez Calls Americans Cowards Before Women».
} 
dades del público; especialmente de las mujeres que según creo forman ahí la parte más importante de la masa de lectores. No vayan a tomar la cosa a mal y digan que yo insulto a la mujer americana». Afortunadamente, insiste en la misma carta, «Este peligro es fácil de evitar. Encárguele al traductor que borre lo de americana y la haga austriaca, o italiana, o rusa; da lo mismo, pues es un personaje de segundo plano y además una aventurera que puede ser de cualquier parte pues todas se parecen». Macrae, en una carta posterior, le quita la idea de la cabeza. No opina que sea algo demasiado grave y, en cualquier caso, el problema lo tendrían si se hiciera pública la modificación.

El libro en el que ha depositado más esperanzas es el que está escribiendo en ese momento: Los enemigos de la mujer. Cierra la trilogía de la Gran Guerra que comenzó con Los cuatro jinetes, por lo que puede aprovechar el tirón del primero y, como lo está escribiendo en ese momento, se puede permitir hacer concesiones al público americano. En esa línea, le cuenta a su editor que, entre otras cosas, «también hablaré de la caballerosa y providencial misión de los Estados Unidos al entrar desinteresadamente en la guerra por la libertad del mundo y hablaré de la figura sublime del Presidente Wilson» (21). En otra carta repite la idea de la noble misión del país en la guerra (29), por lo que no deja de considerar el asunto como importante.

La esperanza de Blasco en el éxito de esa novela es tal que parece faltarle tiempo para que aparezca en inglés. Por ese motivo les propone que se comience la traducción incluso antes de que salga el libro en español. Lo habitual en ese momento, e incluso en la actualidad, salvo cuando se trata de un libro verdaderamente deseado por el público, era esperar a que apareciera en el idioma original para traducirlo después, pero él opina de forma diferente:

En marzo mis editores españoles van a imprimir Los enemigos de la mujer. Si lo desean, les enviaré las hojas que se vayan imprimiendo, de esta manera el traductor podrá ahorrar tiempo y seguir trabajando y así la traducción al inglés saldrá al mismo tiempo que la francesa, y casi al mismo tiempo que la española (34).

Mucho tiempo habrá de pasar para que sea común la publicación de un libro el mismo día en varios idiomas y en diferentes partes del planeta. Esta acción, tomada del mercado cinematográfico, tiene un fin esencialmente comercial, pues la propia presentación se convierte en un hecho noticiable al multiplicar los «estrenos» globalmente. Probablemente Blasco no tenía ese concepto en la cabeza, pero al menos parecía intuir que la publicación del libro podía aprovecharse comercialmente.

Otra sugerencia relacionada con la globalización del mercado editorial, y que como la anterior no se practicará hasta pasadas muchas décadas, es lo que actualmente se llama coedición de libros de gran formato, especialmente caros debido a la abundancia de imágenes de calidad. En esos casos varias editoriales se unen para hacer una gran tirada, que reduce el precio del ejemplar. Pero 
se imprimen solo las imágenes y se deja el hueco para el texto que al ser en tinta negra es mucho más barato. Se reparten entonces los ejemplares entre varios países y cada editorial imprimirá, en el espacio libre, el texto en el idioma respectivo.

Blasco le propone a Macrae la publicación de una biografía suya escrita por el profesor Pitollet en la editorial Prometeo (Pitollet 1921a y 1921b). Lejos de ver la edición del libro como una muestra de vanidad, enfatiza la misma idea que hemos visto de creación de marca: «Creo que esta publicación será útil como propaganda para nuestro trabajo» (107). Con la intención de que no le saliera costoso al americano, le propone algo parecido a lo que ahora se conoce como coedición:

Además, me encargaré de que la editorial Prometeo le envíe como presente las pruebas de las fotos para que pueda publicar el trabajo con las mismas imágenes y así no le costará un centavo. Como usted será capaz de ver, el libro es casi tan interesante como una novela y no le costarán nada los derechos o las imágenes (106).

Ya hemos visto que la editorial Prometeo ponía especial interés en la calidad de las sobrecubiertas, pues se trata del primer reclamo que posee un libro. En esos años no era muy habitual encarecer el producto con una imagen impresa, pero Blasco lo consideraba de capital importancia. Por ese motivo, sigue de cerca las ediciones de sus libros en América. Tras recibir los primeros ejemplares de The Mayflower (Flor de mayo), felicita al editor por el resultado, pero no aduce motivos estéticos, sino comerciales:

Están muy bien y me gusta mucho la presentación del libro. Le felicito por ello. La cubierta en colores está muy bien dibujada y resulta muy atractiva para el público. Un libro así gusta verlo en los escaparates de las librerías y llama la atención del lector. Debía usted hacerles cubiertas de esta misma clase a Blood and Sand y The Shadow of the Cathedral. Podrían resultar muy hermosos y atraer mucho al público hacia estas dos novelas (102).

Descontento como estaba de la cubierta de Blood and Sand, aprovechó cualquier oportunidad para proponer un cambio. A consecuencia de una circunstancia que ahora veremos, Blasco le sugiere añadir una sobrecubierta. Los motivos que aduce son suficientemente claros:

Creo que convendría ponerle una cubierta con colores y figuras, igual a la que llevan otros libros míos. Con una cubierta de colores brillantes, hecha por un buen artista, la novela podría ser expuesta en los escaparates de las librerías y llamaría más la atención que con la cubierta actual, que es solamente impresa y además muy fea (103).

Esto nos lleva al asunto del aprovechamiento de sinergias comerciales. Un mecanismo habitual en la actualidad, pero inexistente en los primeros años del 
siglo XX. El éxito de The Four Horsemen of the Apocalypse había propiciado que se llevara al cine en una gran producción protagonizada por Rudolph Valentino en 1921. Un año más tarde también se rodó Sangre y arena. Sabiendo lo mucho que se publicitaba el cine, el perfecto arte de masas, Blasco se propone aprovechar el tirón de la película para vender más libros y el modo más sencillo de vincular película y novela (acción que se convirtió casi en una norma años después) es añadir una sobrecubierta donde aparezca directamente el cartel de la película. En palabras de Blasco:

Le remito dos ejemplares en inglés del folleto de propaganda del film «Blood and Sand», y un cartel en colores, anunciador de dicho film. El cartel puede servir de modelo para el artista que dibuje la cubierta de mi novela. Si no le gusta esta escena, tal vez puede inspirarse el artista en cualquiera de los grabados que figuran en el folleto del film. De todos modos guárdese el cartel como recuerdo y póngalo en su despacho (105).

No le hicieron caso. Su sugerencia vería la luz veinte años después, en la segunda versión cinematográfica de la novela (1941). Esta vez se añadió una cubierta impresa a tres tintas (los hispánicos rojo y amarillo más negro) con fotografías de los tres protagonistas: Tyrone Power, Linda Darnell y Rita Hayworth. En ese caso dieron un paso más, pues incluyeron fotogramas de la película en el interior, a modo de ilustraciones. Lo que en el mundo anglosajón se denomina photoplay edition.

Pero no era la primera vez que el español intentaba aprovechar acontecimientos externos para darle una nueva vida a alguna de sus novelas. Meses antes de la mencionada película, se hizo una versión teatral de Blood and Sand que recorrió el país. Previendo el éxito, Blasco intenta aprovecharlo para cambiar una cubierta que sabíamos no le gustaba.

Hoy escribo a Valencia a la «Editorial Prometeo» para que me envíen varios grabados que pueden servir de guía al artista que usted designe para que haga la cubierta, con objeto de que no incurra en anacronismos. Tan pronto como tengan estos grabados, dentro de una semana, se los enviaré. No deje de hacer esta cubierta. Daría frescura a nuestra obra, presentándola al público como si fuese nueva (104).

Probablemente ayude a contextualizar mejor la actitud de Blasco Ibáñez si la comparamos con la del otro escritor español que en esas mismas fechas publicó su obra en los Estados Unidos y del que conservamos además parte de su correspondencia sobre el asunto. Nos referimos a Pío Baroja y a Alfred A. Knopf, director de la en aquel entonces joven editorial que llevaba su mismo nombre. Quiso la casualidad que Knopf publicara a ambos por primera vez: $L a$ barraca y La feria de los discretos. El valenciano, como sabemos, vendió el siguiente libro, Los cuatro jinetes del Apocalipsis, a Dutton. Baroja siguió con él y al año apareció César o nada. 
Hasta ese momento no había demasiado trato epistolar entre ellos, pero en un momento dado su cuñada Carmen Monné escribió al norteamericano para pedirle contactos en revistas de aquel país donde poder publicar ${ }^{10}$. Knopf aprovechó la puerta que le había abierto para recriminarle elegantemente que Baroja estuviera negociando a escondidas con la editorial Doubleday. Finalmente el trato no fructificó y Baroja volvió a Knopf, que le publicaría en los años siguientes la trilogía de La lucha por la vida. Podría ser injusto compararlo con la lealtad de Blasco hacia su editorial, teniendo en cuenta que el valenciano fue el primero en irse de Knopf, pero en la correspondencia se intuye que Baroja no tenía intención de marcharse, sino más bien la de mantener su obra publicada en varias casas. La reacción de Knopf es contundente: «esto me forzó, por ahora, a detener la publicación de su trabajo, y esta pérdida de tiempo no fue buena ni para Pío ni para mí»» ${ }^{11}$.

Una vez establecidas las reglas del juego, Knopf inició una labor publicitaria importante. Así como sucedió con Blasco, el primer paso consistía en dar a conocer a Baroja al público lector americano, pero la reacción de Baroja no pudo ser más diferente. Le pide una biografía para moverla por los medios y el vasco responde con una mezcla de humildad y desidia: «La vida de un escritor español actual, por la pequeñez y la miseria de nuestro ambiente, no suele ser una vida decorativa; no hay aventura, ni grandes viajes, ni nada extraordinario». Baroja es consciente del éxito de su compatriota en los Estados Unidos, por lo que no se puede ahorrar un comentario malévolo hacia la diferente actitud del valenciano: «Blasco Ibáñez cuya vida no creo que haya tenido nada de épico, ha convencido a una parte del público cándida y poco... de que es un hombre un poco estilo Renacimiento, de lo que no tiene nada porque en realidad es un pobre hombre, hueco y algo...» ${ }^{12}$. Finalmente accede a escribirle sobre su vida, pero le dice: «dígame usted qué clase de notas acerca de mi vida verdaderas o inventadas, especificándolas con ejemplos, quiere que le envíe y yo lo haré». Al margen de la rectitud o no de sus acciones, lo que denota la última frase es la falta de interés y el poco sentido que encuentra en mostrarse cercano a los lectores. Knopf, lógicamente, solo publicó datos reales sobre su vida.

Algo similar sucedió con una publicación que Knopf cuidaba especialmente. Se trata del Borzoi, una edición no venal y muy cuidada dirigida a autores, libreros, críticos y demás personalidades del mundo del libro (Root 2009, 501). El editor tenía idea de que sirviera de carta de presentación de la editorial, que

10 10-9-1921. Carta de C. Monné de Baroja a Knopf, desde Vera del Bidasoa. Localizada en el archivo Alfred A. Knopf Inc. Records (Harry Ramson Center, Austin, TX). Caja 699 carpeta 6. El resto de la correspondencia que se menciona más abajo se encuentra en el mismo lugar, por lo que indicaremos únicamente la fecha de emisión.

${ }^{11}$ «Its effect was to force me, for the time being, to stop publication of his work, and this lost in time has been good neither for Pio nor myself».

${ }^{12}$ Los puntos suspensivos están en el original. 
acababa de cumplir diez años, y mezclaba por lo tanto el homenaje con la publicidad selectiva. En el volumen escribirían los principales autores que había publicado: Willa Cather, D.H. Lawrence, Kahlil Gibran, Ezra Pound... y le pedía a Baroja que escribiera sobre Unamuno, al que también había editado. La respuesta del vasco es contundente: «Escribir acerca de Unamuno no me entusiasma. Este escritor se ha colocado en una posición tan especial que no se puede hablar de él con libertad», escribe el 13 de abril de 1925. El editor propone entonces que elija él mismo el autor contemporáneo que prefiera, pero a esa oportunidad de hacerse conocer ante un reducido pero selecto número de intelectuales americanos responde con una redacción algo confusa: «me parece difícil hablar de un escritor actual que haga un corto resumen exacto».

Finalmente, en el Borzoi de 1925 no aparecería ningún texto suyo (Ariza 2012, 198). Es notorio el contraste con un Blasco deseoso de publicar cualquier tipo de texto con el fin de darse a conocer.

Una nueva oportunidad que tuvo Baroja de convertirse en una persona conocida en los Estados Unidos fue mediante la publicación de Zalacaín el aventurero en español. Las universidades americanas publicaban numerosas ediciones, anotadas y con introducción explicativa, de libros en español dirigidas a alumnos de idiomas. Knopf le pidió los derechos a Caro Raggio, pero el editor y cuñado de Baroja se los negó debido a que, desde su punto de vista, entrarían en conflicto comercial con sus propios libros. Knopf no comprende la negativa, le asegura que los libros publicados en España no se vendían en los Estados Unidos, por lo que la edición no le robaría ni un solo ejemplar a Caro Raggio. Por el contrario, esta publicación «publicitaría su nombre y su obra entre cientos, si no miles, de jóvenes lectores en la Universidad ${ }^{13}$. Finalmente, Baroja se dejó convencer por los argumentos de su editor norteamericano y accedió a que su Zalacaín se publicara en una edición con introducción, notas y vocabulario de Solomon Rosenberg y Laurence Deane (Baroja 1926).

El contraste entre ambos novelistas es inmenso. La optimista proactividad de Blasco Ibáñez contrasta con la recelosa pasividad de Baroja y, si bien tiene mucho que ver con dos modos de vivir la literatura, puede perfectamente contemplarse como la transición del oficio del escritor hacia el mundo actual. Baroja representaría uno de los últimos escritores artistas: bohemios, antisociales y ensimismados; mientras que Blasco se adelantaría al escritor moderno, novelista de multitudes, con imagen pública y entregado a su público. La paradoja es que, si bien ambos son casi de la misma edad, desde el punto de vista literario cambian las tornas: el noventayochista Baroja es mucho más moderno que el naturalista Blasco. Tal vez el valenciano perdió autenticidad en el proceso, pero dio un paso importantísimo para los hombres de letras, pues con esto demostró por primera vez en España que se podía vivir de la pluma.

13 «But that they would on the contrary advertise your name and work to hundreds, if not thousands of young readers in the universities». 


\section{BIBLIOGRAFÍA CITADA}

Ariza González, Fernando. 2012. «Pío Baroja y Alfred A. Knopf. Cuarenta años de relación editorial». Anales de la Literatura Española Contemporánea 37 (1): 185-205.

Ariza, Fernando. 2018. "Conflictos Internacionales de propiedad intelectual. El caso Blasco Ibáñez en los Estados Unidos». Dicenda. Cuadernos de Filología Hispánica 36: 33-44. https://doi.org/10.5209/DICE.62136

Baroja, Pío. 1926. Zalacaín el aventurero. Edición de Solomon Leopold Millard Rosenberg y Laurence Deane Bailiff. Nueva York: Knopf.

Blasco Ibáñez, Vicente. 1920a. Mexico in Revolution. Traducción de Arthur Livingston y José Padín. New York: E. P. Dutton.

Blasco Ibáñez, Vicente. 1920b. El militarismo mejicano. Valencia: Prometeo.

Blasco Ibáñez, Vicente. 1921. «Novelists as Business Men». The New York Times, 2 enero.

Blasco Ibáñez, Vicente y Francisco Sempere (1999). Epistolario (1901-1917). Introducción, edición y notas de Miguel Herráez. Valencia: Generalitat Valenciana.

Blasco Ibáñez, Vicente y John Macrae. 2017. Correspondencia 1918-1932. Edición traducida con introducción y notas de Fernando Ariza. Saarbrücken: Editorial Académica Española.

Botrel, Jean-François. 2012. «Blasco Ibáñez empresario de sí mismo (Doce cartas a su editor francés, Calmann-Lévy». Revista de Estudios sobre Blasco Ibáñez / Journal of Blasco Ibáñez Studies 1: 147-170.

Caballer Dondarza, Mercedes. 2007. La narrativa española en la prensa estadounidense. Hallazgo, promoción, publicación y crítica (1875-1900). Madrid: Iberoamericana Editorial Vervuert.

Lluch-Prats, Javier. 2012. «Blasco Ibáñez, editor en Madrid». Revista de Estudios sobre Blasco Ibáñez / Journal of Blasco Ibáñez Studies 1: 91-103.

Lluch-Prats, Javier. 2015. «Blasco Ibáñez. El legado de una editorial emblemática: Prometeo (Valencia, 1914)». En Actas del XII Congreso de la Asociación de Historia Contemporánea, 1.621-1.635. Madrid: Universidad Autónoma de Madrid.

Moses, Montrose J. 1919. «Blasco Ibáñez the Approachable». The New York Times, 2 noviembre.

Montague, James J. 1920. «More Truth than Poetry». The Washington Post, 3 Dic., p. 11.

Pitollet, Camille. 1921a. V. Blasco lbáñez; ses romans et le roman de sa vie. Paris: CalmannLévy.

Pitollet, Camille. 1921b. V. Blasco Ibáñez. Su novela y la novela de su vida. Valencia: Prometeo.

Root, Amy. 2009. «Designing the Borzoi: Alfred A. Knopf, Inc. Creates a Brand of Excellence, 1915-29». The Papers of the Bibliographical Society of America 103 (4): 497-513.

Sánchez García, Raquel. 2001. «Diversas formas para nuevos públicos». En Historia de la edición en España, 1836-1936, Jesús A. Martínez, 241-268. Madrid: Marcial Pons.

Varela, Javier. 2017. El último conquistador: Blasco Ibáñez (1867-1928). Madrid: Tecnos.

Fecha de recepción: 15 de julio de 2017.

Fecha de aceptación: 29 de diciembre de 2017. 